\title{
Constructing Teacher Performance Evaluation System about Chinese Research Universities
}

\author{
Fangyuan Liu, Jialin Yu \\ Northeast Agricultural University, Heilongjiang Province, China \\ liufangyuan617@163.com,momo0343@hotmail.com
}

\begin{abstract}
Constructing a scientific and reasonable teacher performance evaluation system was a guarantee for research universities to motivate teachers' creative enthusiasm, optimize teaching staff, promote discipline construction and establish highlevel research universities. This paper analyzed the problems of evaluation system in research universities in China, and proposed the constructing principles of teacher performance evaluation system. It was explored that the differentiated quantitative evaluation indicators according to the subject discipline, staff category, and team structure and so on, while taking into account the sustainable assessment model combining the performance quantitative indicator evaluation and the developing qualitative evaluation. system.

Index Terms - research university, job performance, evaluation
\end{abstract}

\section{Research background}

University teacher evaluation system is a hot issue in higher education research, also an important part of the personnel system reform in colleges and universities. In particular, research universities have taken the tasks of subject construction and cultivating innovative talents. The significance of these tasks and the teachers' varied complexity increase the difficulty of establishing scientific teacher evaluation system. Xiong Lan, et al. pointed out that the main problems of university teachers' evaluation were concept deviations, narrow content and unitary form, administrative procedures, poor evaluator diathesis and so on. Gu Cheng, et al. believed that the current university teacher evaluation systems and standards did not fully reflect the content of requirements of teachers' quality, and the objectivity, authority and impartiality of the evaluation results should be improved.

2. The problems of research university teachers' performance evaluation system in China

\section{A. The lack of differentiation of the evaluation indicator system}

There is disciplinary difference, position difference and personal difference in universities, therefore the performance evaluation of university teachers should reflect the differences, and could not apply the unified evaluation criteria. The universities sponsored by "211 Project" and "985 Project" and a number of universities with graduate student fostering system present the objective to construct the research universities, but the level differences between disciplines in universities are great. Many colleges and universities go after upgrading blindly and the trend of teacher evaluation system is similar, without considering their school's stage of development, levels and characteristics. Hence the teachers can not use the teacherevaluation system as the correct "baton" to contribute to the subject, which leads to the departure from the school's development targets and the waste of human and material resources.

\section{B. The partial evaluation indicator system}

In United States, university teachers' workload is specified as the three parts of teaching, research and service, three-in-one professional teacher responsibility. However, at present, the main indicators of college teacher evaluation system in China are two quantitative indicators of teaching and research. The examination of research values the fund and quantity, but ignores the influence of the outcome. The evaluation of academic articles pays attention to the publication level and the published amount, but ignores the quality of the papers. The evaluation of teaching work emphasizes the teaching workload, while neglects the updates of teaching content, the teaching results, the improvement in teaching methods and quality and so forth. The current evaluation system has not attached importance to service work. In fact, the teachers have to complete not only teaching and research tasks, but also to undertake specialized tasks such as specialty, curriculum and subject construction.

\section{The deviation of the evaluation index system orientation}

The evaluation index system is the "baton" of teacher development. In the present context that universities are generally fickle, many universities assess teachers according to the standard of application for Master and Doctorial degree granting units and for key disciplines. Teachers were evaluated according to the project and thesis level, and the scientific research was bounded up with the teacher's incentives, promotions, salaries and status. Under this value orientation, university teachers will no doubt focus on making up the number of papers and research projects, and it is hard to devote the energies to innovation and teaching reform. Accordingly, the spirit lost, the individuality and innovation depressing appear, and it is difficult for the teachers to cultivate talents with innovative spirit and innovative ability. In addition, the current teacher evaluation system is basically individual-based, and there are no evaluation and encouragement mechanism for teams. Therefore, the "fighting alone" situation appears, and it is difficult to form a sustainable innovation team. It hams the discipline condensing and undertaking the major national scientific research projects. 
3. The construction principle of the performance evaluation system for research universities teachers' in China

Along with the deepening of personnel system reform in universities, the establishment of post management system, and the refinement of professional technique, a scientific teacher evaluation system is more urgently needed. Setting up the teacher performance evaluation system needs to embody the request of the university's development targets, to attain the teacher motivation, and to promote the university's comprehensive development.

\section{A. Clarifying evaluation system direction, considering both the universities' target realization and teacher development}

The teacher evaluation system should be a system of circulation. The performance evaluation plays function of direction, encouragement and promotion through the feedback and control effect of the evaluation process. In this circulation, the university teachers continuously review and improve their work, and their working enthusiasm, innovation and initiative is fully mobilized. Then the universities give impetus to their work and realize the target positioning.

Modern Humanistic Management Theory states that all the management work must be people-oriented in the modern society. Teachers are the main bodies of teaching and research work, so the universities need to care teachers' development and progress, to improve their subject consciousness and their own quality. Evaluation index system should coincide with the development of universities. The fundamental purpose of teachers' performance evaluation is to establish evaluation criteria and to mobilize their working enthusiasm, innovation and initiative according to the school's operation idea and targets. In the meantime, the purpose is to advance the teacher's individual development, to strengthen the construction of teachers' team, to improve the teaching level and research level, and to increase the efficiency ultimately. At the same time, the system design should consider the coordination of long-term and short-term goal and avoids the short-term abuses.

\section{B. Respecting the specialty of the teachers' work, considering both teaching and scientific research}

Teacher performance appraisal should fully reflect the teacher's teaching investment and the teaching and scientific research achievements. Most colleges directly regard teacher performance as the amount of published academic papers, academic works and the number of classes, and take these as the criteria of promotion, bonus distribution and so on. Thereby teachers in teaching and scientific research process put more emphasis on the pursuit of quantity, ignore the quality improvement. They look forward for instant success, weaken the incentive function of performance evaluation, and directly affect the quality of teaching and research.

The present teacher performance evaluation ignores the hidden work, the complexity, comprehensiveness and longterm characteristic. There is no comprehensive system to reflect the rich, valuable work content, which is easy to cause contingent and limited evaluation results. The evaluation of the research university teachers should be mainly in scientific research but taking teaching into account. Besides paying attention to quantitative results, importance should be attached to the qualitative evaluation such as innovation, personnel training, the influence of academic achievements and moralities.

\section{Constructing different job performance evaluation system according to category}

In general, research universities are multi-disciplinary comprehensive universities. The inevitable differences of the subject development stage and development goals of disciplines lead to different goal orientation of discipline development and the level of teacher team. Discipline construction is the main task of the development of the research university that requires the teachers who attach equal importance to scientific research and teaching to take up the majority. However, due to the systematicness and complexity of the discipline construction and scientific research tasks, different types of teachers play different roles, such as teaching, researching, popularizing the projects, and assisting research. Therefore, there are a number of series taking different emphasis but all indispensable.

\section{A. Classifying according to subject}

a) Natural sciences: There are many natural science disciplines that are paid importance on by different universities, and those disciplines are at different stage of development. Universities should distinguish the teachers' requirements in strong disciplines, weak disciplines and developing disciplines, fully research and analyze the current teacher performance level, combine the teachers' overall level of the subject in the society with the school development targets, and establish reasonable evaluation criteria. The evaluation indicators should fully embody the teacher's sense of achievement, exert teachers' enthusiasm, and imbue the teachers with motivation and hope.

b) Social Sciences: Social sciences generally include liberal arts, history, philosophy, management and so on. The articles of these disciplines are different from that of natural sciences in their quantity, quality and embodying situation. Thus the analysis of the development level of the subject and the determination of the appropriate quantitative criteria needs to be according to the published papers and research projects in the field. For instance, SSCI, CSSCI collection of articles in social sciences are not completely equal to SCI, EI collection in natural sciences. The funding amount of Social Science projects is very small but the importance is not, so it cannot simply quantitatively compare with the natural science project with thousand of millions funds.

\section{B. Classifying according to the personnel series}

a) Teaching and scientific research: the teachers of this series have to undertake the task of teaching and training undergraduate students and postgraduate, so the evaluation 
should focus on the number and level of published papers, the capabilities of undertaking the state longitudinal research project and the contribution to the discipline.

b) Scientific research: these staff need to assume a small amount of teaching tasks, but should emphasize the number and level of published articles and the ability to undertaking national major scientific research projects and enterprises vertically project.

c) Engineering: this category needs not to focus on the article publishing and longitudinal projects, but these teachers need to emphasize the abilities of achievement transformation and significant engineering development and application.

d) Teaching: the requirements of article publication and vertical project are not key-point. The evaluation should focus on the quantity, quality, and teaching achievements (such as teaching-reform articles, textbooks and monographs and award-winning results).

e) Teaching and research auxiliary: there are no studentfostering and teaching requirements. However, the emphasis should be on the auxiliary role of teaching and research. Taking the laboratory personnel as an example, the appraisal should emphasize their contribution on the analysis test of scientific research project, and the ability to develop instruments and updating testing methods.

\section{Building an independent team evaluation system}

Research universities undertake huge teaching and research tasks and face high quality requirements, so they need to form an innovative team to respond to the teaching and research requirements. Different categories of personnel have to work together, divide labor, learn from each other, integrate resources, and concert efforts.

Research universities encourage teachers to form voluntary teaching or scientific research team in accordance with the discipline development needs. The determination of the number and level of team position setting should be based on the proportion of job structure and the performance and contribution on a team basis. The team assessment is neither aimed at the assessment of the individual, nor a series of assessment. Therefore the evaluation index system should be more comprehensive, systematic and objective. The evaluation of team performance is necessary to have "hard indicators" describing the actual outputs and "soft indicators" describing the team spirit and culture. The "hard" and "soft" indicators should combine together and be given the corresponding weights according to the characteristics of the subject development. For the establishment of the set of comprehensive scientific evaluation system, quantitative methods should be dominant, and qualitative methods supplemented.

\section{D.The combination of quantitative and qualitative evaluation indicators}

Scientific and moderate quantitative criteria are necessary. In Britain and United States, the quantity and quality of published papers and research projects are also important indicators. It is just avoided that the overweight quantitative indicators exert enormous pressure to teachers. But on the basis of quantitative evaluation, the importance is put on the qualitative appraisal such as innovative personnel training, team building, discipline construction and professional ethics. Especially, some academic leaders should not be required to meet specific quantitative indicators, but to focus on their discipline leadership and human resource construction. Within a certain range, universities can refer to the lifetime professor system in United States. For the teachers who have worked for a certain number of years and have made significant contributions, universities should protect them and give them some free time and space to do innovative research and leading the subject direction.

\section{Conclusion}

Scientific and rational job performance evaluation system for the teachers is an important guarantee for the sustainable development of research universities. Research universities are main duty-bearers for the cultivation of innovative talents in China, thus the teacher evaluation should pay more attention to sustainable development and mobilize their enthusiasm to carry out innovative research and develop innovative talents. In research universities, teachers' individual differences, the target stages of the subject development and disciplinary building urgently require constructing teacher job performance evaluation system according to category differences, in order to adapt to the different development needs of teachers, scientifically evaluate each teacher's objective contribution and to promote the comprehensive development of research universities.

\section{Acknowledgment}

Heilongjiang Provincial Department of Education Humanities and social science projects(Item Number 1252b002).

\section{References}

[1] Y. Fu and Y. Xu, Performance appraisal and performance management, Beijing: Electronic Industry Press, 2009.

[2] H. Liu, The College Team Innovation Performance Assessment: Models and empirical research, Beijing: Tsinghua University Press, 2007.

[3] W. Lu, et al, "Constructing the teacher evaluation system based on the concept of modern education evaluation," Higher Education Management, 2009 (2): 61-66.

[4] H. Jiang, "From the Berkeley management perspective talking to the American research university teacher performance assessment," Higher Agricultural Education, 2007 (1): 88-91.

[5] G. Liu, et al, "Research university teacher evaluation system," Chinese University Teachers, 2010 (3): 26-31. 